\title{
Local Morphology Predicts Functional Organization of Experienced Value Signals in the Human Orbitofrontal Cortex
}

\author{
Yansong Li, ${ }^{1,2}$ Guillaume Sescousse, ${ }^{1,2 \star}$ Céline Amiez, ${ }^{2,3 *}$ and Jean-Claude Dreher ${ }^{1,2}$ \\ ${ }^{1}$ Reward and Decision-Making Team, Cognitive Neuroscience Center, CNRS UMR 5229, 69675 Bron, France, 2Université Claude Bernard Lyon 1, 69100 \\ Villeurbanne, France, and 'Institut National de la Santé et de la Recherche Médicale U846, Stem Cell and Brain Research Institute, 69500 Bron, France
}

\begin{abstract}
Experienced value representations within the human orbitofrontal cortex (OFC) are thought to be organized through an antero-posterior gradient corresponding to secondary versus primary rewards. Whether this gradient depends upon specific morphological features within this region, which displays considerable intersubject variability, remains unknown. To test the existence of such relationships, we performed a subject-by-subject analysis of fMRI data taking into account the local morphology of each individual. We tested 38 subjects engaged in a simple incentive delay task manipulating both monetary and visual erotic rewards, focusing on reward outcome (experienced value signal). The results showed reliable and dissociable primary (erotic) and secondary (monetary) experienced value signals at specific OFC sulci locations. More specifically, experienced value signal induced by monetary reward outcome was systematically located in the rostral portion of the medial orbital sulcus. Experienced value signal related to erotic reward outcome was located more posteriorly, that is, at the intersection between the caudal portion of the medial orbital sulcus and transverse orbital sulcus. Thus, the localizations of distinct experienced value signals can be predicted from the organization of the human orbitofrontal sulci. This study provides insights into the anatomo-functional parcellation of the anteroposterior OFC gradient observed for secondary versus primary rewards because there is a direct relationship between value signals at the time of reward outcome and unique OFC sulci locations.
\end{abstract}

Key words: experienced value; fMRI; local morphology; orbitofrontal cortex; reward

\section{Introduction}

Over the past decades, there has been an explosion in the research on understanding how the brain represents the experienced value of rewards, which are computed at the time of reward outcome. One key brain area implicated in this process is the orbitofrontal cortex (OFC) (Kringelbach, 2005; Wallis, 2007; Rolls et al., 2008; Mainen and Kepecs, 2009; Haber and Knutson, 2010; Peters and Büchel, 2010; Grabenhorst and Rolls, 2011; Ruff and Fehr, 2014). This brain region has been shown to serve a common currency function, allowing the value of different types of rewards to be

Received July 21, 2014; revised Dec. 1, 2014; accepted Dec. 5, 2014.

Author contributions: Y.L., G.S., and J.-C.D. designed research; G.S. performed research; Y.L., G.S., and C.A. analyzed data; Y.L., C.A., and J.-C.D. wrote the paper.

This work was supported by ANR-11-EMCO-01101 HEIDI to J.-C.D. It was performed within the framework of the LABEX ANR-11-LABEX-0042 of Université de Lyon, within the program Investissements d'Avenir (ANR-11-IDEX0007) operated by the French National Research Agency (ANR). Y.L. was supported by a PhD fellowship from Pari Mutuel Urbain funded to J.-C.D., G.S. was supported by a French Ministry of Research and the Medical Research Foundation scholarship. We thank the staff of CERMEP-Imagerie du Vivant for helpful assistance with data collection.

The authors declare no competing financial interests.

*G.S. and C.A. contributed equally to this study.

G. Sescousse's present address: Radboud University Nijmegen, Donders Institute for Brain, Cognition and Behaviour, Nijmegen, The Netherlands.

Correspondence should be addressed to Dr. Jean-Claude Dreher, Reward and Decision-making Team, Cognitive Neuroscience Center, CNRS UMR5229, 67 Bd Pinel, 69675 Bron, France. E-mail: dreher@isc.cnrs.fr or liyansongrenzs@gmail.com.

DOI:10.1523/JNEUROSCI.3058-14.2015

Copyright $\odot 2015$ the authors $\quad 0270-6474 / 15 / 351648-11 \$ 15.00 / 0$ represented and compared on a common value scale (Sugrue et al., 2005; Murray et al., 2007; Kim et al., 2011; Levy and Glimcher, 2012; Bartra et al., 2013). Despite its centrality in the representation of values across reward types, the potential specialization of distinct OFC subregions in value representation has become a topic of increasing interest. Consistent with a popular hypothesis proposing the existence of an antero-posterior functional gradient reflecting the abstractness of reinforcers in the OFC (Kringelbach and Rolls, 2004; Kringelbach, 2005), we have recently found a dissociation between experienced values of erotic/monetary rewards and the posterior/anterior OFC (Sescousse et al., 2010, 2013a). This finding is corroborated by recent research (Klein-Flügge et al., 2013; McNamee et al., 2013) and metaanalyses comparing the neural representation of value for different reward modalities (Sescousse et al., 2013b; Clithero and Rangel, 2014).

The OFC is a vast and heterogeneous region, characterized by considerable intersubject morphological variability. The morphology of the human orbitofrontal sulci has been classified into three major types (Types I, II and III, in order of frequency) within each hemisphere (Chiavaras and Petrides, 2000; Petrides and Mackey, 2006). This raises an important question: whether and how the posterior versus anterior topographic organization of value signals maps onto particular parts of this morphologically variable OFC region. Given that group-averaged fMRI findings usually ignore this important aspect of the data, subject- 


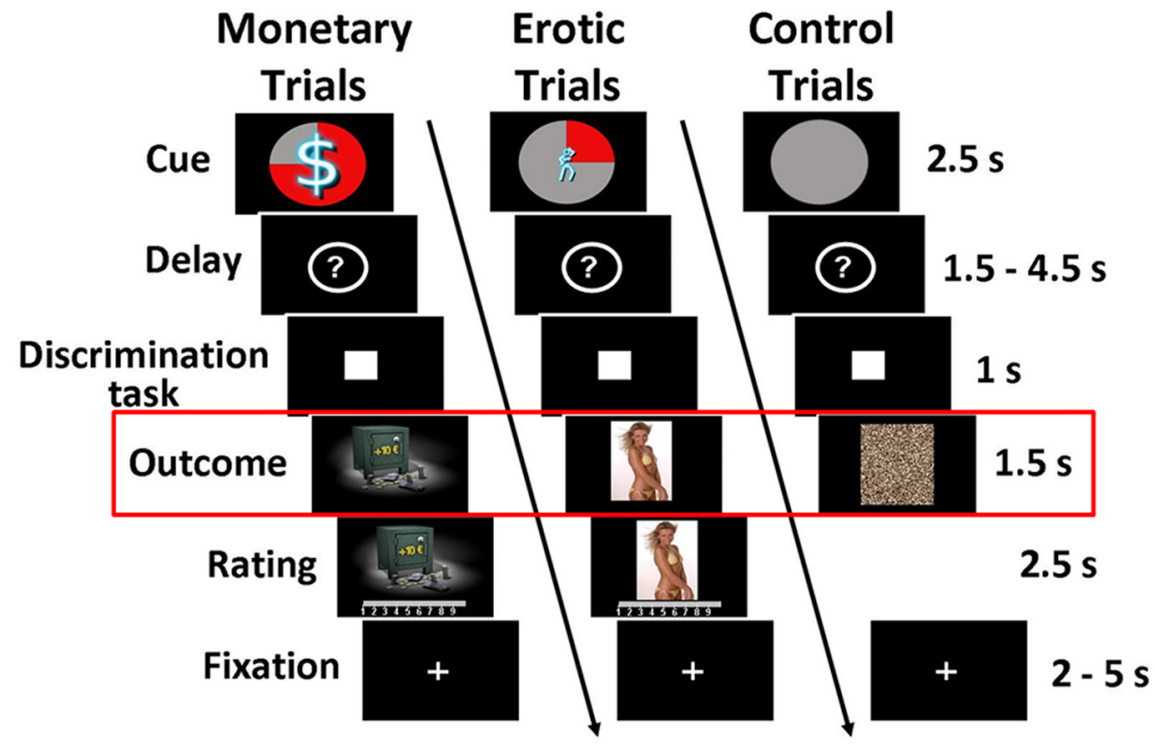

Figure 1. Incentive delay task. Subjects first saw a cue informing them about the type (pictogram), intensity (size of pictogram), and probability (pie chart) of an upcoming reward. Three cases are represented here: $75 \%$ chance of receiving a large amount of money (left), a 25\% chance of seeing a low erotic content picture (middle), and a sure chance of getting nothing (control trials, right). Then the cue was replaced by a question mark, symbolizing a delay period during which a pseudorandom draw was performed according to the announced probability. Following this anticipation phase, subjects had to perform a target discrimination task within $<1 \mathrm{~s}$. The target was either a triangle (left button press required) or a square (right button press required). Both their performance and the result of the pseudorandom draw determined the nature of the outcome. In rewarded trials, subjects saw a monetary amount displayed on a safe (high or low amount, left) or an erotic picture (with high or low erotic content, middle), and had to provide a hedonic rating on a continuous scale. In nonrewarded and control trials, subjects saw a scrambled picture (right). Triangle in red denotes that our analysis focuses on the reward outcome phase.

by-subject assessment of potential links between function and the local morphology could help solve this issue. This approach has already been demonstrated to be valid in understanding the precise morphological-functional relationships in other brain regions, including the dorsal premotor cortex (Amiez et al., 2006), the supplementary eye field (Grosbras et al., 1999; Amiez and Petrides, 2009), the inferior frontal junction (Derrfuss et al., 2012), the mid-cingulate cortex (Amiez et al., 2013; Amiez and Petrides, 2014), and the angular gyrus (Segal and Petrides, 2013).

Here, to investigate how the posterior versus anterior topographic organization of value signals relates to individual morphological variability in the orbitofrontal sulci, we performed subject-by-subject analysis on the data from two previously published fMRI studies using the same experimental protocol, which consistently showed the antero-posterior dissociation between experienced value signals elicited by monetary and erotic rewards in the OFC (Sescousse et al., 2010, 2013a). Our results clearly demonstrate that dissociable experienced value signals for monetary and erotic rewards relate to specific morphological features of the human OFC.

\section{Materials and Methods}

Subjects. A group of 38 healthy right-handed subjects were included in our current data analysis (age, mean $\pm \mathrm{SD}=27.5 \pm 6.8$ years). All of them were heterosexual males with no history of neurological and psychiatric disorders. Data were from two groups of subjects (18 and 20 subjects, respectively), which have been described in two separate previous fMRI studies using the same experimental protocol (Sescousse et al., 2010, 2013a). All subjects gave written informed consent before being part of the experiment, which was approved by the local ethics committee.

Sexual arousability was assessed at intake using the Sexual Arousability Inventory (Hoon and Chambless, 1998). The mean Sexual Arousability Inventory (SAI) score was $91.1 \pm 12.0$, which is comparable with the score reported in the reference population (90.6 \pm 14.7$)$ (Hoon and Chambless, 1998). Depressive symptoms were measured with the Beck Depression Inventory (Beck and Beck, 1972 ) in Group 1 (mean score: $1.4 \pm 2.0$ ) and the Hospital Anxiety and Depression scale (Zigmond and Snaith, 1983) in Group 2 (mean score: $3.4 \pm 2.3$ ). Subjects in Group 2 also underwent a psychiatric interview and were screened for psychiatric disorders (as part of the matching with pathological gamblers). In both groups, subjects who reported no interest whatsoever in erotica or showing low sexual arousability (cutoff SAI: 69) were excluded from the study. Moreover, subjects showing depressive symptoms (as assessed by the psychiatric interview in Group 2 or based on a cutoff of 6 on the Beck Depression Inventory in Group 1) were also excluded.

To further ensure that all subjects would be in a similar state of motivation to see erotic stimuli, we asked them to avoid any sexual contact during a period of $24 \mathrm{~h}$ before the scanning session. We also sought to enhance the motivation for money by telling the subjects that the financial compensation for their participation would amount to the winnings accumulated in one of the runs of the study. For ethical reasons, though, and unbeknownst to the subjects, they all received a fixed amount at the end of the experiment.

Experiment task. As described in the original studies (Sescousse et al., 2010, 2013a), each trial consisted of an anticipation phase, a discrimination task, and an outcome phase (Fig. 1). During anticipation, subjects saw one of 12 explicit cues announcing the type (monetary/erotic), probability $(25 \% / 50 \% / 75 \%)$, and intensity (low/high) of an upcoming reward (2.5 s). An additional control cue was associated with a null reward probability. After a variable delay period (question mark representing a pseudo-random draw, 1.5-4.5 s), subjects were asked to perform a target discrimination task. If they answered correctly within $<1 \mathrm{~s}$, they were then allowed to view the outcome of the pseudo-random draw. In rewarded trials, outcomes took the form of an erotic image or a sum of money displayed on a safe (1.5 s), whose intensity was high or low depending on the preceding cue. Following each reward outcome, participants had $2.5 \mathrm{~s}$ to provide a hedonic rating by moving a cursor along a $1-9$ scale ( 1 , very little pleased; to 9 , very highly pleased). In nonrewarded and control trials, participants were presented with "scrambled" pictures. A fixation cross was finally used as an intertrial interval of variable length $(2-5 \mathrm{~s})$.

The task was divided into several runs of 57 trials each. Subjects from Group 1 performed four runs (i.e., 228 trials), whereas subjects from Group 2 performed three runs (i.e., 171 trials, due to time constraints). Each run included four repetitions of each cue, with the exception of the control condition, repeated nine times. Within each run, the order of the different conditions was pseudo-randomized and optimized for further signal deconvolution. The order of the runs was counterbalanced between subjects. Before scanning, all subjects were given verbal instructions and familiarized with the cognitive task in a short training session.

Task stimuli. Two categories (high and low intensity) of erotic pictures and monetary gains were used. Nudity being the main criteria driving the reward value of erotic stimuli, we separated them into a "low-intensity" group displaying females in underwear or bathing suits and a "highintensity" group displaying naked females in an inviting posture. Each erotic picture was presented only once during the course of the task to avoid habituation. A similar element of surprise was introduced for the monetary rewards by randomly varying the amounts at stake: the low amounts were 1,2 , or $3 €$, and the high amounts were 10,11 , or $12 €$. The pictures displayed in nonrewarded and control trials were scrambled 


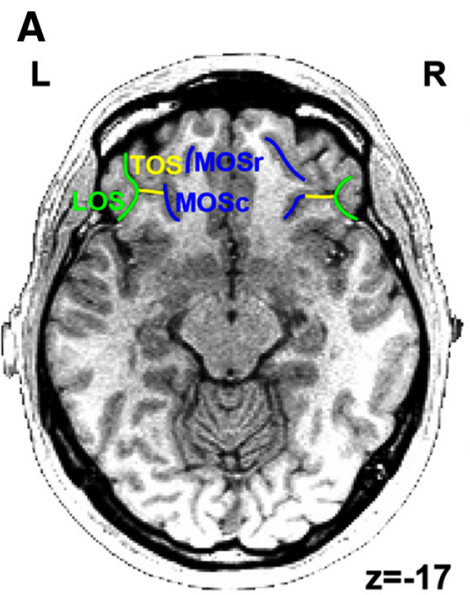

Pattern Type I
B

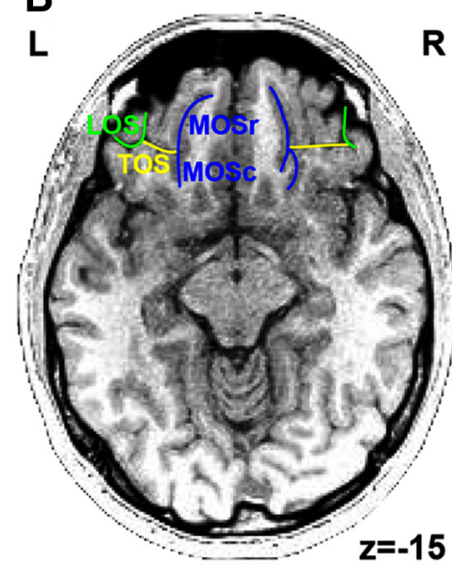

Pattern Type II
C

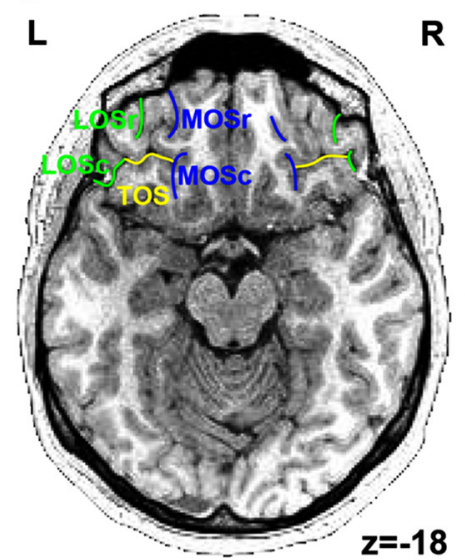

Pattern Type III

Figure 2. Example of each orbitofrontal subcogyral type on the axial view of T1 images. $A$, Type I: rostral and caudal portions of the LOS (green) are continuous; rostral and caudal segments of the MOS (blue) are not connected. B, Type II: both medial (blue) and lateral (green) orbital sulci are continuous and are jointed by the horizontally oriented TOS (yellow). C, Type III: both medial (blue) and lateral (green) orbital sulci are separate. $r$, Rostral; c, caudal; L, left hemisphere; R, right hemisphere.

versions of the pictures used in rewarded trials and hence contained the same information in terms of chromaticity and luminance.

Primary rewards are classically considered to have an innate value and to be essential for the maintenance of homeostasis and reproduction, whereas secondary rewards are not directly related to survival and only gain value through learned association with lower-level rewards. According to this definition, one may argue that erotic images may operate as secondary reinforcers, in the sense that the subjects may interpret the images as signifying the availability of primary reinforcement. However, there are reasons to believe that erotic images can be considered as primary reinforcers in the context of our task. Indeed, these images did not predict the availability of primary reinforcers (e.g., physical sex) and thus cannot be considered as secondary reinforcers simply serving as Pavlovian cues. Moreover, erotic images were rewarding by themselves, as demonstrated by the fact that: (1) hedonic ratings of erotic stimuli are similar to those observed for money (Sescousse et al., 2010, 2013a); (2) subjects are willing to work for them, as demonstrated by the short reaction times and by physical effort exerted to observe them for longer period of time (Prévost et al., 2010). Similar observations have been made in male rhesus macaques who are ready to sacrifice fluid rewards for the opportunity to view female perinea (Deaner et al., 2005). In everyday life, many men are willing to exchange money for the opportunity to view pictures or movies with sexual content (magazines, internet), again suggesting that erotic images are by themselves rewarding.

fMRI data acquisition. Imaging was performed on a $1.5 \mathrm{~T}$ Siemens Sonata scanner using an 8-channel head coil. Each of the functional runs contained 296 volumes. Twenty-six interleaved slices parallel to the AC-PC line were acquired per volume (field of view $=220 \mathrm{~mm}$, matrix $64 \times 64$, voxel size $=3.4 \times 3.4 \times 4 \mathrm{~mm}$, gap $=0.4 \mathrm{~mm})$ using a gradient-echo echoplanar (EPI) $\mathrm{T}^{\star}$-weighted sequence (repetition time $=2500 \mathrm{~ms}$, echo time $=60 \mathrm{~ms}$, flip angle $=90^{\circ}$ ). To improve the local field homogeneity and hence minimize susceptibility artifacts, a manual shimming was performed within a rectangular region, including the OFC and the basal ganglia. A high-resolution T1-weighted structural scan was also acquired in each subject.

fMRI data analysis. Preprocessing and statistical analyses on our fMRI data have been described previously (Sescousse et al., 2010, 2013a, 2014). Our subject-by-subject analyses focused on the outcome phase. Given our a priori hypothesis of the involvement of the OFC in representing experienced value signals, we used the left and right OFC as ROI, which were defined using the Automatic Anatomical Labeling atlas (TzourioMazoyer et al., 2002), implemented in the software WFU PickAtlas (Maldjian et al., 2003). As described in our previous fMRI study (Sescousse et al., 2010), brain activity responding specifically to monetary (or erotic) reward outcome resulted from the contrast "monetary reward $>$ erotic reward" (or erotic reward $>$ monetary reward), masked inclusively with the contrast "monetary reward $>$ control" (or "erotic reward $>$ control") and exclusively with the contrast "erotic reward > control" (or "monetary reward $>$ control"). The results at the individual subject level are reported at a peak-level threshold of $p<0.05$, corrected for multiple comparisons.

OFC sulcogyral pattern classification. The OFC sulcogyral patterns were identified using the medical image analysis software (MRIcro, http:// www.mccauslandcenter.sc.edu/mricro/) and classified according to the criteria described by Chiavaras and Petrides (2000). With regard to the orbitofrontal sulci in the human brain, four main sulci have been identified, namely, the olfactory, medial (MOS), lateral (LOS), and transverse (TOS) orbital sulci. On the basis of the continuity of the medial and lateral orbital sulci (MOS and LOS, respectively), Chiavaras and Petrides (2000) classified the morphology of the human orbitofrontal sulci into three main types (Type I, II, and III) in each hemisphere (Fig. 2). In Type I, rostral and caudal portions of the LOS (LOSr and LOSc) are connected to one another, whereas the rostral and caudal portions of the MOS (MOSr and MOSc) are clearly separate (Fig. 2A). Compared with the Type I pattern, the distinct feature of the Type II is that rostral portions of both LOS and MOS are connected to their caudal portions, forming the continuous MOS and LOS, and both sulci are jointed by the horizontally oriented TOS (Fig. 2B). In Type III, the critical distinct characteristic is that the rostral and caudal parts of both MOS and LOS are clearly disconnected (Fig. 2C). The sulcus continuity was determined by evaluating several adjacent axial slices rather than focusing on one slice. The OFC sulcogyral pattern classification in each hemisphere of the 38 subjects was done by Y.L. and C.A. separately, blinded to the subject group.

\section{Results}

Morphological features of the orbitofrontal cortex in all subjects

Table 1 shows the frequency of the OFC sulcogyral patterns across 38 subjects. As described in Table 1, the Type I pattern was observed in $50 \%$ of hemispheres. Among them, this pattern type was found in the left hemisphere of $42 \%$ of subjects and in the right hemisphere of $58 \%$ of subjects, indicating that this type pattern was observed more frequently in the right hemisphere than in the left. Compared with the Type I pattern, the Type II pattern was observed in 33\% of hemispheres among the subjects. Unlike the Type I pattern, the Type II pattern was seen more often in the left hemisphere of subjects (37\%) than in the right (29\%). 
A

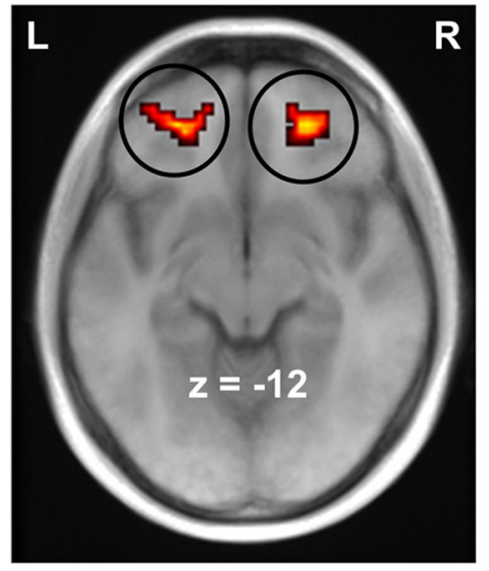

Anterior OFC

\section{Monetary reward-specific brain activity}

B

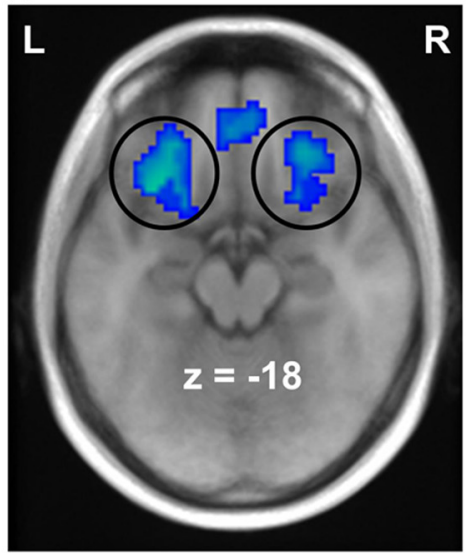

Posterior OFC

\section{Erotic reward-specific brain activity}

Figure 3. Functional antero-posterior dissociation in the OFC depending on reward type. Brain regions responding specifically to monetary reward outcome are displayed in red-yellow $(\boldsymbol{A})$, whereas those responding specifically to erotic reward outcome are displayed in blue-green $(\boldsymbol{B})$. The group results clearly demonstrated an antero-to-posterior gradient of experienced value representations in the $0 \mathrm{FC}$, corresponding to concrete-to-abstract rewards. Activations are overlaid on an average anatomical scan of all subjects ( $p<0.05$, whole-brain corrected). L, Left hemisphere; $R$, right hemisphere.

Finally, the remaining subjects (17\%) showed the Type III pattern. Like the Type II pattern, the Type III pattern was also expressed more often in the left hemisphere of subjects $(21 \%)$ than in the right $(13 \%)$. The observations described above are consistent with previous literature (Chiavaras and Petrides, 2000).

\section{fMRI results}

Group analysis: distinct experienced value signals in the OFC Our previously published fMRI studies have revealed reward value-specific representations in the OFC at the time of reward outcome, showing an antero-posterior dissociation between experienced value signals elicited by monetary and erotic rewards in the OFC (Sescousse et al., 2010, 2013a). Here, we pooled these two independent fMRI data together and examined the brain responses to each type of reward outcome separately. Consistent with our published analyses, monetary rewards specifically recruited the anterior OFC (MNI $x, y, z:-22,45,-12$, $\mathrm{T}=5.92 ; 21,42,-18, \mathrm{~T}=5.76$ ) (Fig. $3 A$ ). In contrast, erotic rewards elicited activity specifically in the posterior part of the OFC $(-24,27,-12, \mathrm{~T}=11.34 ; 27,33,-15, \mathrm{~T}=8.95)$ (Fig. 3B). These results clearly demonstrate a double dissociation between monetary/erotic rewards and the anterior/posterior OFC.

\section{Individual subject analysis}

The above conventional group data $\mathrm{AMRI}$ analysis does not allow the assessment of the relationships between the locations of experienced value signals for monetary and erotic rewards and specific morphological features of the OFC. Therefore, given the strong intersubject variability within the region (Table 1), only a subject-by-subject analysis can allow the determination of these anatomo-functional relationships.

Importantly, value signals at the time of monetary reward outcome were systematically located in the MOSr in all subjects in both hemispheres, in all OFC sulcogyral pattern types (Tables 2, 3, and 4). Indeed, in subjects showing the Type I pattern of anatomical organization of the OFC (MOS is separate and LOS is continuous; Fig. 2A), the monetary reward outcome-related activity was located in the MOSr in both hemispheres (Table 2; Fig. $4 A$ ). In subjects showing the Type II pattern of anatomical organization (both MOS and LOS are continuous; Fig. 2B), the monetary reward outcome-related activity was located in the MOSr in both hemispheres (Table 3; Fig. 4B). Similarly, in subjects showing the Type III pattern of anatomical organization of this region (both MOS and LOS are separate; Fig. $2 C)$, the monetary reward-related activity was located in the MOSr in both hemispheres (Table 4; Fig. 4C).

In contrast, the value signals at the time of erotic reward outcome were systematically located more posteriorly, that is, in the joint between TOS and MOSc in all subjects, in all OFC sulcogyral pattern types (Tables 5, 6, and 7). Indeed, in subjects showing the Type I pattern of anatomical organization of the OFC (MOS is separate and LOS is continuous; Fig. 2A), the erotic reward outcome-elicited signal was located in the joint between TOS and MOSc in both hemispheres (Table 5; Fig. $4 D)$. In subjects showing the Type II pattern of anatomical organization (both MOS and LOS are continuous; Fig. 2B), this signal was located in the joint between TOS and MOSc in both hemispheres as well (Table 6; Fig. 4E). As observed in the Type I and Type II, in subjects showing the Type III pattern of anatomical organization of this region (both MOS and LOS are separate; Fig. $2 C$ ), the signal was also located in the joint between TOS and MOSc in both hemispheres (Table 7; Fig. $4 F)$.

Moreover, to illustrate the above relationship across all subjects, we projected the peak of experienced values signals for monetary and erotic rewards in each hemisphere onto the three OFC sulcogyral pattern types. Figure $5 A-C$ shows the locations of those two value signals for all subjects in both hemispheres grouped by the Type I. As shown in Figure 5, although the sulci locations differ among subjects, the link between value signals at the time of reward outcome and specific sulci locations (MOSr or the intersection between TOS and MOSc) does not change. It also clearly reveals an antero-posterior gradient organization of these two value signals corresponding to secondary versus primary rewards. These observations in the Type I are further supported by the findings from the Type II and Type III. Figure $6 A, B$ and Figure $6 C, D$ show the locations of both types of experienced value signals for all subjects in both hemispheres grouped by Type II and Type III, respectively. With regard to the Type II and Type III, what we found is the same as described in the Type I by showing the dependency of value signals at the time of reward outcome on specific sulci locations and antero-posterior gradient organization of both types of value signals.

Finally, we computed how far the individual activations are located from the average activation of all subjects for both types of rewards. On average, the distance across $x, y, z$ coordinates between the individual activations and the average activation of all subjects for monetary reward outcomes was $9.4 \pm 3.5 \mathrm{~mm}$ in the left hemisphere and $8.1 \pm 3.1 \mathrm{~mm}$ in the right hemisphere. For erotic reward outcomes, the mean distance across $x, y, z$ 
Table 1. Distributions of orbitofrontal sulcogyral pattern of individual subjects

\begin{tabular}{lllr}
\hline & \multicolumn{3}{l}{ Orbitofrontal sulcogyral pattern types, N (\%) } \\
\cline { 2 - 4 } & I & II & \multicolumn{1}{l}{ III } \\
\hline Left & $16(42)$ & $14(37)$ & $8(21)$ \\
Right & $22(58)$ & $11(29)$ & $5(13)$ \\
Total (left + right) & $38(50)$ & $25(33)$ & $13(17)$ \\
\hline
\end{tabular}

Table 2. The localization of experienced value signals for monetary reward grouped by the pattern Type $I^{a}$

\begin{tabular}{|c|c|c|c|c|c|c|}
\hline \multirow[b]{2}{*}{ Subjects } & \multirow[b]{2}{*}{ Location } & \multicolumn{3}{|c|}{ MNI coordinates } & \multirow[b]{2}{*}{ T value } & \multirow{2}{*}{$\begin{array}{l}\text { Distanc } \\
(\mathrm{mm})\end{array}$} \\
\hline & & $x$ & $y$ & $z$ & & \\
\hline \multicolumn{7}{|l|}{ Left hemisphere } \\
\hline S1 & MOSr & -18 & 51 & -12 & 6.26 & 7.21 \\
\hline $\mathrm{S} 2$ & $*$ & $*$ & $*$ & $*$ & $*$ & $*$ \\
\hline S6 & MOSr & -24 & 42 & -18 & 3.13 & 7.00 \\
\hline 57 & MOSr & -18 & 39 & -27 & 2.63 & 16.64 \\
\hline S9 & MOSr & -24 & 42 & -12 & 2.41 & 3.61 \\
\hline $\mathrm{S} 10$ & MOSr & -18 & 39 & -21 & 2.71 & 11.53 \\
\hline S11 & * & $*$ & $*$ & $*$ & * & $*$ \\
\hline S14 & $*$ & $*$ & $*$ & $*$ & $*$ & $*$ \\
\hline S17 & MOSr & -18 & 51 & -15 & 4.28 & 7.81 \\
\hline S19 & MOSr & -21 & 39 & -27 & 3.61 & 16.19 \\
\hline $\mathrm{S} 23$ & MOSr & -21 & 39 & -24 & 3.81 & 13.45 \\
\hline $\mathrm{S} 28$ & MOSr & -18 & 45 & -18 & 3.91 & 7.21 \\
\hline S31 & MOSr & -18 & 42 & -21 & 4.50 & 10.30 \\
\hline S32 & MOSr & -21 & 45 & -27 & 4.93 & 15.03 \\
\hline S34 & MOSr & -21 & 39 & -21 & 2.97 & 10.86 \\
\hline S37 & * & $*$ & $*$ & $*$ & $*$ & $*$ \\
\hline Mean $\pm S D$ & & $-20 \pm 2.4$ & $42.6 \pm 4.5$ & $-20.3 \pm 5.4$ & & \\
\hline \multicolumn{7}{|c|}{ Right hemisphere } \\
\hline S3 & * & * & * & $*$ & * & $*$ \\
\hline S6 & MOSr & 15 & 54 & -15 & 3.92 & 13.75 \\
\hline S7 & MOSr & 18 & 42 & -27 & 3.01 & 9.49 \\
\hline S9 & $*$ & $*$ & $*$ & $*$ & $*$ & $*$ \\
\hline $\mathrm{S} 10$ & $*$ & $*$ & $*$ & $*$ & $*$ & $*$ \\
\hline S11 & MOSr & 18 & 45 & -18 & 2.99 & 4.24 \\
\hline $\mathrm{S} 12$ & * & $*$ & $*$ & $*$ & $*$ & $*$ \\
\hline $\mathrm{S} 13$ & MOSr & 18 & 54 & -18 & 2.64 & 12.37 \\
\hline $\mathrm{S} 16$ & $*$ & $*$ & $*$ & $*$ & * & \\
\hline S17 & MOSr & 18 & 54 & -18 & 3.75 & 12.37 \\
\hline S19 & $*$ & $*$ & $*$ & $*$ & $*$ & $*$ \\
\hline S22 & * & * & $*$ & $*$ & $*$ & * \\
\hline $\mathrm{S} 23$ & $*$ & $*$ & $*$ & $*$ & $*$ & $*$ \\
\hline$S 25$ & MOSr & 18 & 39 & -15 & 3.18 & 5.20 \\
\hline S27 & MOSr & 18 & 51 & -12 & 4.41 & 9.95 \\
\hline $\mathrm{S} 28$ & MOSr & 18 & 39 & -18 & 2.97 & 4.24 \\
\hline $\mathbf{S} 29$ & MOSr & 24 & 42 & -24 & 3.55 & 6.71 \\
\hline S31 & MOSr & 15 & 54 & -18 & 6.77 & 13.42 \\
\hline S32 & MOSr & 15 & 45 & -27 & 3.17 & 11.22 \\
\hline S33 & MOSr & 21 & 51 & -18 & 2.74 & 9.00 \\
\hline S34 & MOSr & 18 & 42 & -18 & 2.69 & 3.00 \\
\hline S37 & MOSr & 18 & 48 & -21 & 4.55 & 7.35 \\
\hline Mean $\pm S D$ & & $18 \pm 2.4$ & $47.1 \pm 5.8$ & $-19.1 \pm 4.3$ & & \\
\hline
\end{tabular}

${ }^{a}$ Distance refers to how far individual activations across $x, y, z$ coordinates are located from the average activation of all subjects for monetary reward.

*No activation survives a corrected threshold in the OFC.

coordinates between individual activations and the average activation of all subjects was $10.7 \pm 3.4 \mathrm{~mm}$ in the left hemisphere and $7.0 \pm 3.4 \mathrm{~mm}$ in the right hemisphere. In addition, the distance across $x, y, z$ coordinates of the locations of activation on each individual from the average activation of all subjects for monetary or erotic reward outcomes are further reported in Tables 2 to 7 .

Together, these results not only establish the link between value signals and specific sulci locations in the OFC but also demonstrate an antero-posterior gradient corresponding to
Table 3. The localization of experienced value signals for monetary reward grouped by the pattern Type II ${ }^{a}$

\begin{tabular}{|c|c|c|c|c|c|c|}
\hline \multirow[b]{2}{*}{ Subjects } & \multirow[b]{2}{*}{ Location } & \multicolumn{3}{|c|}{ MNI coordinates } & \multirow[b]{2}{*}{ T value } & \multirow{2}{*}{$\begin{array}{l}\text { Distance } \\
(\mathrm{mm})\end{array}$} \\
\hline & & $x$ & $y$ & $z$ & & \\
\hline \multicolumn{7}{|l|}{ Left hemisphere } \\
\hline S4 & MOSr & -18 & 45 & -21 & 4.37 & 9.85 \\
\hline S5 & MOSr & -21 & 42 & -18 & 5.07 & 6.78 \\
\hline S8 & $*$ & * & $*$ & * & * & * \\
\hline $\mathrm{S} 13$ & MOSr & -18 & 48 & -18 & 4.44 & 7.81 \\
\hline S15 & MOSr & -24 & 54 & -12 & 2.66 & 9.22 \\
\hline $\mathbf{S} 20$ & * & * & * & * & * & * \\
\hline S21 & MOSr & -18 & 48 & -12 & 5.88 & 5.00 \\
\hline S26 & MOSr & -24 & 42 & -18 & 4.76 & 7.00 \\
\hline S27 & MOSr & -18 & 51 & -6 & 6.36 & 9.38 \\
\hline$\$ 29$ & MOSr & -24 & 42 & -24 & 3.35 & 12.53 \\
\hline $\mathrm{S} 30$ & * & * & $*$ & * & * & * \\
\hline S33 & $\mathrm{MOSr}$ & -24 & 42 & -18 & 3.05 & 7.00 \\
\hline S36 & * & * & $*$ & * & * & * \\
\hline $\mathrm{S} 38$ & * & * & $*$ & * & * & * \\
\hline Mean \pm SD & & $-21 \pm 3$ & $46 \pm 4.5$ & $-16.3 \pm 5.4$ & & \\
\hline \multicolumn{7}{|l|}{ Right hemisphere } \\
\hline S4 & MOSr & 15 & 48 & -21 & 3.08 & 9.00 \\
\hline S5 & $\mathrm{MOSr}$ & 18 & 45 & -21 & 4.27 & 5.20 \\
\hline $\mathrm{S} 8$ & $\mathrm{MOSr}$ & 24 & 45 & -24 & 3.14 & 7.35 \\
\hline S14 & * & * & * & * & * & * \\
\hline S15 & $*$ & $*$ & $*$ & $*$ & $*$ & * \\
\hline$\$ 20$ & MOSr & 18 & 42 & -15 & 2.92 & 4.24 \\
\hline S21 & MOSr & 24 & 51 & -15 & 5.37 & 9.95 \\
\hline S26 & MOSr & 24 & 42 & -12 & 4.79 & 6.71 \\
\hline S35 & MOSr & 27 & 42 & -21 & 2.58 & 6.71 \\
\hline S36 & * & * & $*$ & * & * & * \\
\hline $\mathrm{S} 38$ & * & $*$ & $*$ & $*$ & $*$ & * \\
\hline Mean \pm SD & & $21.4 \pm 4.4$ & $45 \pm 3.5$ & $-18.4 \pm 4.4$ & & \\
\hline
\end{tabular}

${ }^{a}$ Distance refers to how far individual activations across $x, y, z$ coordinates are located from the average activation of all subjects for monetary reward.

${ }^{*}$ No activation survives a corrected threshold in the OFC.

Table 4. The localization of experience value signals for monetary reward grouped by the pattern Type III $^{a}$

\begin{tabular}{|c|c|c|c|c|c|c|}
\hline \multirow[b]{2}{*}{ Subjects } & \multirow[b]{2}{*}{ Location } & \multicolumn{3}{|c|}{ MNI coordinates } & \multirow[b]{2}{*}{ T value } & \multirow{2}{*}{$\begin{array}{l}\text { Distance } \\
(\mathrm{mm})\end{array}$} \\
\hline & & $x$ & $y$ & $z$ & & \\
\hline \multicolumn{7}{|l|}{ Left hemisphere } \\
\hline S3 & * & * & * & * & * & * \\
\hline S12 & MOSr & -21 & 45 & -21 & 3.46 & 9.06 \\
\hline$S 16$ & MOSr & -18 & 54 & -12 & 2.53 & 9.85 \\
\hline$S 18$ & * & * & * & * & * & * \\
\hline$S 22$ & * & * & * & * & * & * \\
\hline S24 & MOSr & -24 & 48 & -12 & 3.96 & 3.61 \\
\hline S25 & MOSr & -21 & 45 & -24 & 4.57 & 12.04 \\
\hline S35 & * & * & $*$ & * & * & * \\
\hline Mean $\pm S D$ & & $-21 \pm 2.4$ & $48 \pm 4.2$ & $-17.3 \pm 6.2$ & & \\
\hline \multicolumn{7}{|l|}{ Right hemisphere } \\
\hline S1 & * & * & * & * & * & * \\
\hline S2 & MOSr & 21 & 42 & -24 & 2.56 & 6.00 \\
\hline $\mathrm{S} 18$ & MOSr & 24 & 42 & -27 & 4.19 & 9.49 \\
\hline S24 & * & * & * & * & * & * \\
\hline S30 & * & * & * & * & * & * \\
\hline Mean \pm SD & & $22.5 \pm 2.1$ & $42 \pm 0$ & $-25.5 \pm 2.1$ & & \\
\hline
\end{tabular}

${ }^{a}$ Distance refers to how far individual activations across $x, y, z$ coordinates are located from the average activation of all subjects for monetary reward.

*No activation survives a corrected threshold in the OFC.

abstract-to-concrete rewards in this region. In addition, these results also indicate a gradient in the degree of precision that one can obtain in the location of experienced value signals depending on the method used for analysis. Whereas group analysis reveals dissociable experienced value signals for erotic and monetary rewards in the OFC, a subject-by-subject analysis taking into ac- 


\section{Pattern Type I \\ Pattern Type II \\ Pattern Type III \\ Monetary reward-specific brain activity in the OFC}
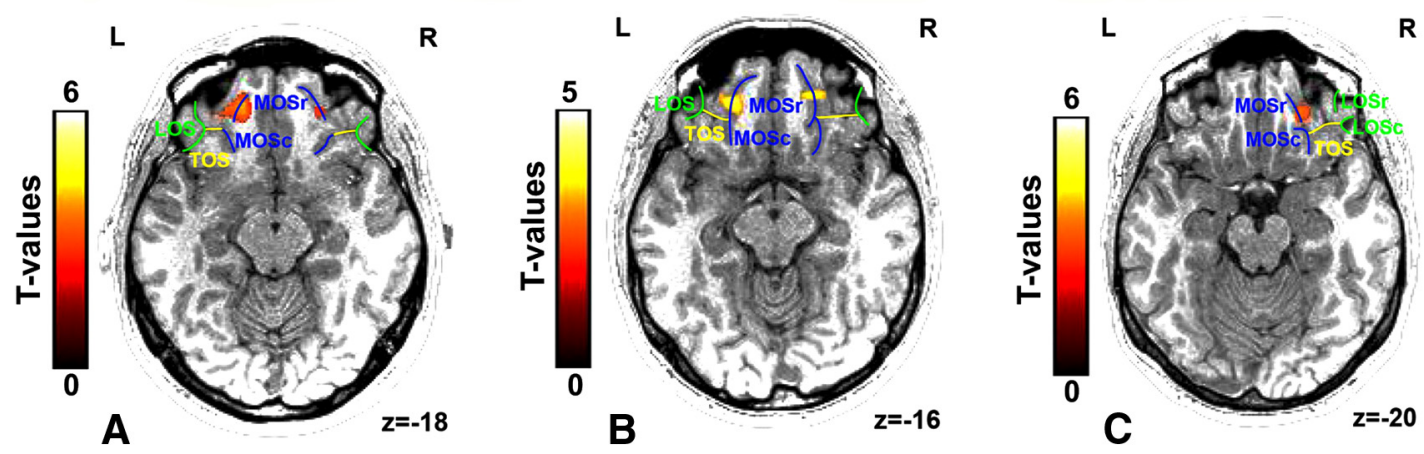

Erotic reward-specific brain activity in the OFC
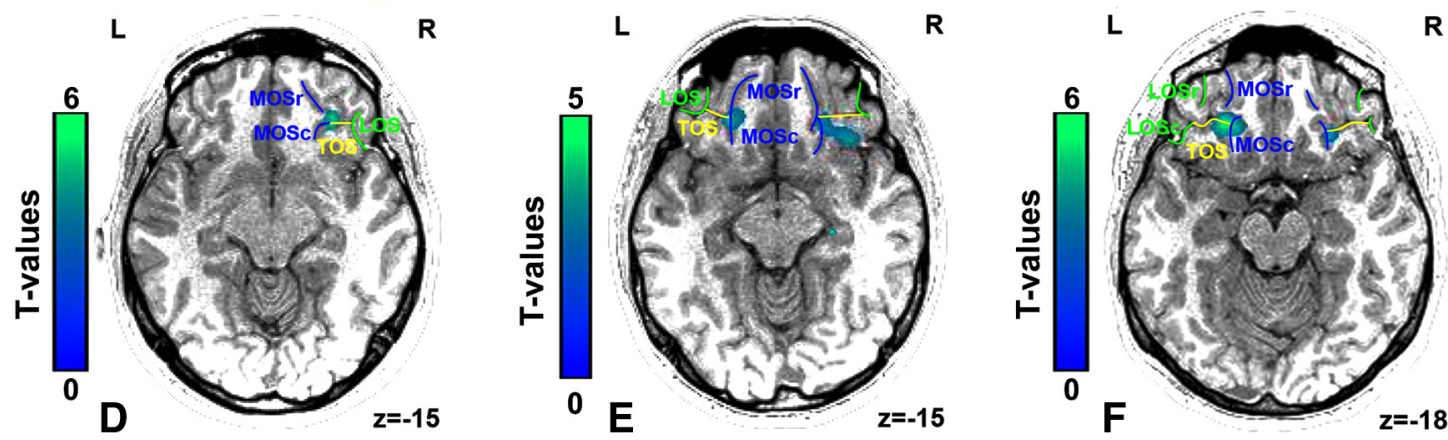

$\mathbf{R}$

Figure 4. Example patterns of anatomo-functional organization of the OFC observed in typical individual subjects. The monetary-specific activity is always located in the MOSr, in all the OFC sulcogyral pattern types $(\boldsymbol{A}-\boldsymbol{C}$. In contrast, the erotic-specific activity is consistently located in the joint between the MOSC and TOS, in all OFC sulcogyral pattern types (D-F). On the axial plane of subjects' anatomical image, sulci of pattern Type I, II, III are color-coded in green, yellow, and blue, respectively. r, Rostral; c, caudal; L, left hemisphere; R, right hemisphere.

count morphological features of this brain region clearly shows that the value signal at the time of monetary reward outcome was located in the MOSr, whereas the value signal at the time of erotic reward outcome was located at the intersection between the TOS and MOSc.

\section{Discussion}

In the present study, the reanalysis of our previously published data confirmed the original findings showing an anterior-toposterior gradient of experienced value representations, corresponding to concrete-to-abstract rewards. Specifically, we found the antero-posterior dissociation between experienced value signals elicited by monetary and erotic rewards in the OFC: monetary rewards preferentially engaged the anterior part of the OFC, whereas erotic rewards preferentially engaged its posterior part. More importantly, our current analysis moves an important step forward toward a more detailed characterization of the anatomofunctional relationship between the local morphology of the OFC and reward type-dependent activation at the reward outcome phase. Monetary reward outcome-dependent activations were systematically located in the rostral portion of the MOS, whereas erotic reward outcome-dependent activations were located posteriorly, at the junction between the caudal portion of the MOS and TOS. Thus, the present subject-by-subject analysis demonstrates that the experienced value signals related to secondary and primary rewards can be predicted based on the relative locations of specific OFC sulci. This suggests that one could predict locations of experienced value signals for primary and secondary rewards in new set of subjects just based on their OFC anatomy.
According to the architectonic subdivisions of the human orbital and medial surface (Ongür and Price, 2000; Ongür et al., 2003; Price, 2007), the MOSr from which the value signal at the time of monetary reward outcome arises is located in area 111, which is occupied by granular cortex in the rostral OFC. In contrast, the intersection between the MOSc and TOS, from which the experienced value signal at the time of erotic reward outcome arises, is located in area 131, which is in the posterior medial orbital surface and is occupied by dysgranular cortex. This area 131 is distinguished from the anterior area 111 by the lack of a continuous granular layer. In addition, a recent cytoarchitectonic study on the medial region of the human OFC quantified the changes in the density of specific cortical layers between architectonic areas. The results of this study revealed an increase in the density of layer IV from a posterior (areas 14c, 14r, and 13) to anterior OFC (areas 11 and $11 \mathrm{~m}$ ) direction (Mackey and Petrides, 2009). These observations suggest that the anteroposterior gradient of experienced value signals may be a consequence of fine grained differences in sensory inputs arriving to architectonic areas 111 and 131.

It is interesting to relate the functiono-anatomical relationship revealed by the current study to functional networks sharing connections with different OFC subregions. Two distinct networks arising from the central orbital cortex and the medial prefrontal cortex have been proposed (Ongür and Price, 2000; Price, 2006, 2007). One system, the orbital network, involves most of the areas in the central orbital cortex. The other system, called the medial prefrontal network, includes areas on the medial wall and 
Table 5. The localization of experienced value signals for erotic reward grouped by the pattern Type $I^{a}$

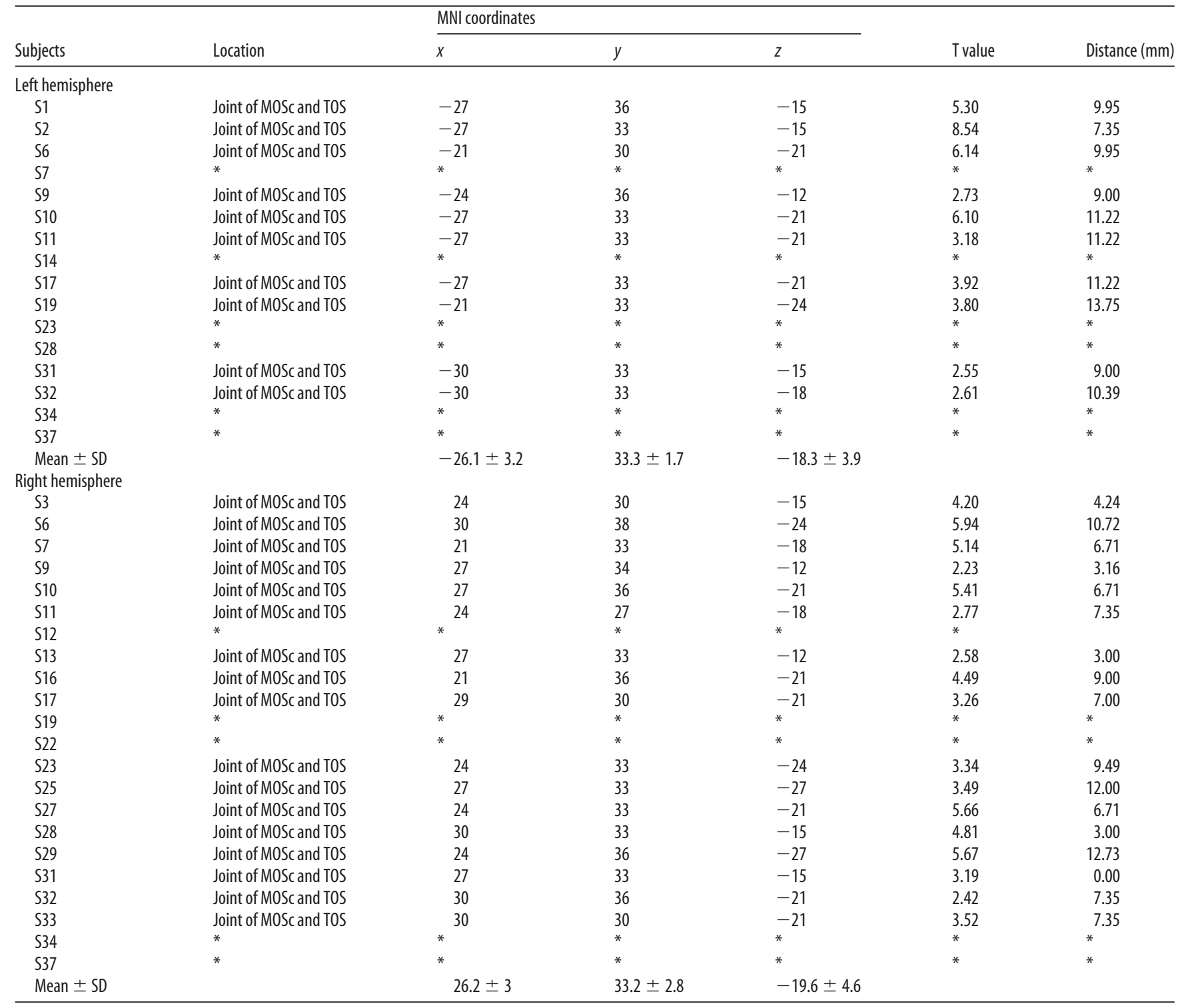

${ }^{a}$ Distance refers to how far individual activations across $x, y, z$ coordinates are located from the average activation of all subjects for erotic reward.

*No activation survives a corrected threshold in the $\mathrm{OFC}$.

two areas in the postero-lateral orbital cortex. The locations of the two sulci associated with the two types of value signals observed in the present study belong to the orbital network, which receives inputs from several sensory modalities. Projections from different sensory modalities terminate especially in the posterior part of the orbital network (Carmichael and Price, 1996; Ongür and Price, 2000) whereas area 131 mainly receives somatosensory input. Because such somatosensory information has been argued to play a central role when processing visual sexual stimuli (Mouras, 2007), this could explain why area 131 plays an important role in processing erotic rewards. In contrast, all of the areas in the posterior part of the orbital network converge on more anterior areas, which provide the basis for integration between several sensory modalities. Area 111 has been shown to integrate inputs from several modalities from areas in the posterior parts of the orbital network (Carmichael and Price, 1996; Ongür and Price, 2000; Price, 2006, 2007). These hierarchical corticocortical connections between areas within the orbital network could be an important factor enabling this antero-posterior OFC gradient.
In addition to corticocortical connections supporting the functional antero-posterior gradient in the OFC, recent structural connectivity analyses of the OFC subregions further support our current findings. Whereas the posterior OFC is heavily connected with less cytoarchitecturally developed limbic and paralimbic areas, the anterior OFC shows its densest connectivity to cytoarchitecturally well-developed cortical areas, both in nonhuman primates (Barbas and Pandya, 1989; Carmichael and Price, 1995) and in humans (Price, 2006). This observation is further complemented by a recent study on the functional parcellation of the OFC based on resting-state connectivity patterns with other brain regions (Kahnt et al., 2012). This study identified six OFC subdivisions with homogeneous functional connectivity profiles. The location of experienced value for monetary rewards corresponds to the central OFC according to these subdivisions. In contrast, the location of experienced value for erotic rewards corresponds to the posterior-central OFC subdivision. Based on the connectivity profiles of these two subdivisions, the central OFC showed functional connectivity with the anterior insula, the 
Table 6. The localization of experienced value signals for erotic reward grouped by the pattern Type II ${ }^{a}$

\begin{tabular}{|c|c|c|c|c|c|c|}
\hline \multirow[b]{2}{*}{ Subjects } & \multirow[b]{2}{*}{ Location } & \multicolumn{3}{|l|}{ MNI coordinates } & \multirow[b]{2}{*}{ T value } & \multirow[b]{2}{*}{ Distance $(\mathrm{mm})$} \\
\hline & & $x$ & $y$ & $z$ & & \\
\hline \multicolumn{7}{|l|}{ Left hemisphere } \\
\hline S4 & Joint of MOSc and TOS & -28 & 30 & -21 & 5.65 & 10.30 \\
\hline S8 & Joint of MOSC and TOS & -24 & 30 & -21 & 5.00 & 9.49 \\
\hline$S 13$ & Joint of MOSC and TOS & -33 & 33 & -9 & 4.80 & 11.22 \\
\hline S15 & Joint of MOSC and TOS & -27 & 30 & -15 & 3.71 & 5.20 \\
\hline$S 26$ & Joint of MOSC and TOS & -27 & 30 & -18 & 4.28 & 7.35 \\
\hline S27 & Joint of MOSC and TOS & -24 & 36 & -18 & 5.59 & 10.82 \\
\hline$S 29$ & Joint of MOSC and TOS & -24 & 36 & -27 & 5.03 & 17.49 \\
\hline S30 & Joint of MOSC and TOS & -33 & 30 & -21 & 4.10 & 13.08 \\
\hline S33 & Joint of MOSC and TOS & -27 & 33 & -24 & 6.37 & 13.75 \\
\hline S36 & Joint of MOSC and TOS & -33 & 33 & -21 & 3.04 & 14.07 \\
\hline S5 & * & * & $*$ & $*$ & $*$ & * \\
\hline S8 & $*$ & $*$ & $*$ & $*$ & $*$ & $*$ \\
\hline S14 & Joint of MOSC and TOS & 18 & 33 & -24 & 2.55 & 12.73 \\
\hline S15 & Joint of MOSC and TOS & 33 & 33 & -12 & 5.78 & 6.71 \\
\hline$S 20$ & $*$ & * & $*$ & $*$ & $*$ & $*$ \\
\hline$S 21$ & Joint of MOSc and TOS & 27 & 33 & -12 & 4.00 & 3.00 \\
\hline$S 26$ & Joint of MOSC and TOS & 27 & 33 & -12 & 4.67 & 3.00 \\
\hline S35 & & * & * & * & * & * \\
\hline S36 & Joint of MOSc and TOS & 24 & 36 & -27 & 3.43 & 12.73 \\
\hline S38 & $*$ & $*$ & $*$ & $*$ & * & * \\
\hline Mean $\pm S D$ & & $25.5 \pm 4.9$ & $33 \pm 1.9$ & $-18.5 \pm 7.2$ & & \\
\hline
\end{tabular}

${ }^{a}$ Distance refers to how far individual activations across $x, y, z$ coordinates are localized from the average activation of all subjects for erotic reward.

*No activation survives a corrected threshold in the OFC.

Table 7. The localization of experienced value signals for erotic reward grouped by the pattern Type $\mathrm{III}^{a}$

\begin{tabular}{|c|c|c|c|c|c|c|}
\hline \multirow[b]{2}{*}{ Subjects } & \multirow[b]{2}{*}{ Location } & \multicolumn{3}{|c|}{ MNI coordinates } & \multirow[b]{2}{*}{ T value } & \multirow[b]{2}{*}{ Distance (mm) } \\
\hline & & $x$ & $y$ & $z$ & & \\
\hline \multicolumn{7}{|l|}{ Left hemisphere } \\
\hline S3 & Joint of MOSc and TOS & -27 & 33 & -12 & 5.26 & 6.71 \\
\hline $\mathrm{S} 12$ & * & * & * & * & * & * \\
\hline S16 & Joint of MOSC and TOS & -24 & 30 & -27 & 4.61 & 15.30 \\
\hline $\mathrm{S} 18$ & Joint of MOSC and TOS & -27 & 33 & -18 & 4.33 & 9.00 \\
\hline S22 & Joint of MOSC and TOS & -24 & 30 & -18 & 4.01 & 6.71 \\
\hline S24 & Joint of MOSC and TOS & -24 & 33 & -15 & 2.82 & 6.71 \\
\hline S25 & Joint of MOSC and TOS & -30 & 36 & -30 & 4.05 & 21.00 \\
\hline S35 & Joint of MOSC and TOS & -21 & 30 & -21 & 2.41 & 9.95 \\
\hline Mean $\pm S D$ & & $-25.3 \pm 2.9$ & $32.1 \pm 2.3$ & $-20.1 \pm 6.4$ & & \\
\hline \multicolumn{7}{|c|}{ Right hemisphere } \\
\hline S1 & Joint of MOSC and TOS & 27 & 36 & -22 & 5.42 & 7.62 \\
\hline S2 & Joint of MOSC and TOS & 27 & 30 & -21 & 5.65 & 6.71 \\
\hline S18 & Joint of MOSc and TOS & 30 & 30 & -18 & 3.83 & 5.20 \\
\hline S24 & * & * & $*$ & $*$ & $*$ & $*$ \\
\hline S30 & Joint of MOSC and TOS & 27 & 30 & -18 & 3.32 & 4.24 \\
\hline Mean \pm SD & & $27.8 \pm 1.5$ & $31.5 \pm 3$ & $-19.8 \pm 2.1$ & & \\
\hline
\end{tabular}

${ }^{a}$ Distance refers to how far individual activations across $x, y, z$ coordinates are localized from the average activation of all subjects for erotic reward.

*No activation survives a corrected threshold in the OFC.

midcingulate cortex, and subcortically with the dorsal (head of caudate nucleus) and the ventral striatum. In contrast, the posteriorcentral OFC exhibited functional connectivity with hypothalamic basal forebrain, ventral striatum, and the parahippocampal gyrus (Kahnt et al., 2012). Together, this functional connectivity pattern of these two OFC subdivisions is consistent with the anatomofunctional relationship reported in the current study.

In addition, our findings may have important implications for exploring the relationships between the locations of other types of value signals and local morphology in the OFC. For example, a recent fMRI study, which found distinct decision value computations induced by primary and secondary rewards, also reported evidence for such a gradient in the ventromedial prefrontal cortex/OFC (McNamee et al., 2013). Using the subject-by-subject analysis to explore how the local morphology relates to the dissociable decision value signals in this region will greatly contributes to our understanding of how the decision value signals map onto the underlying anatomical features in this region. More- 

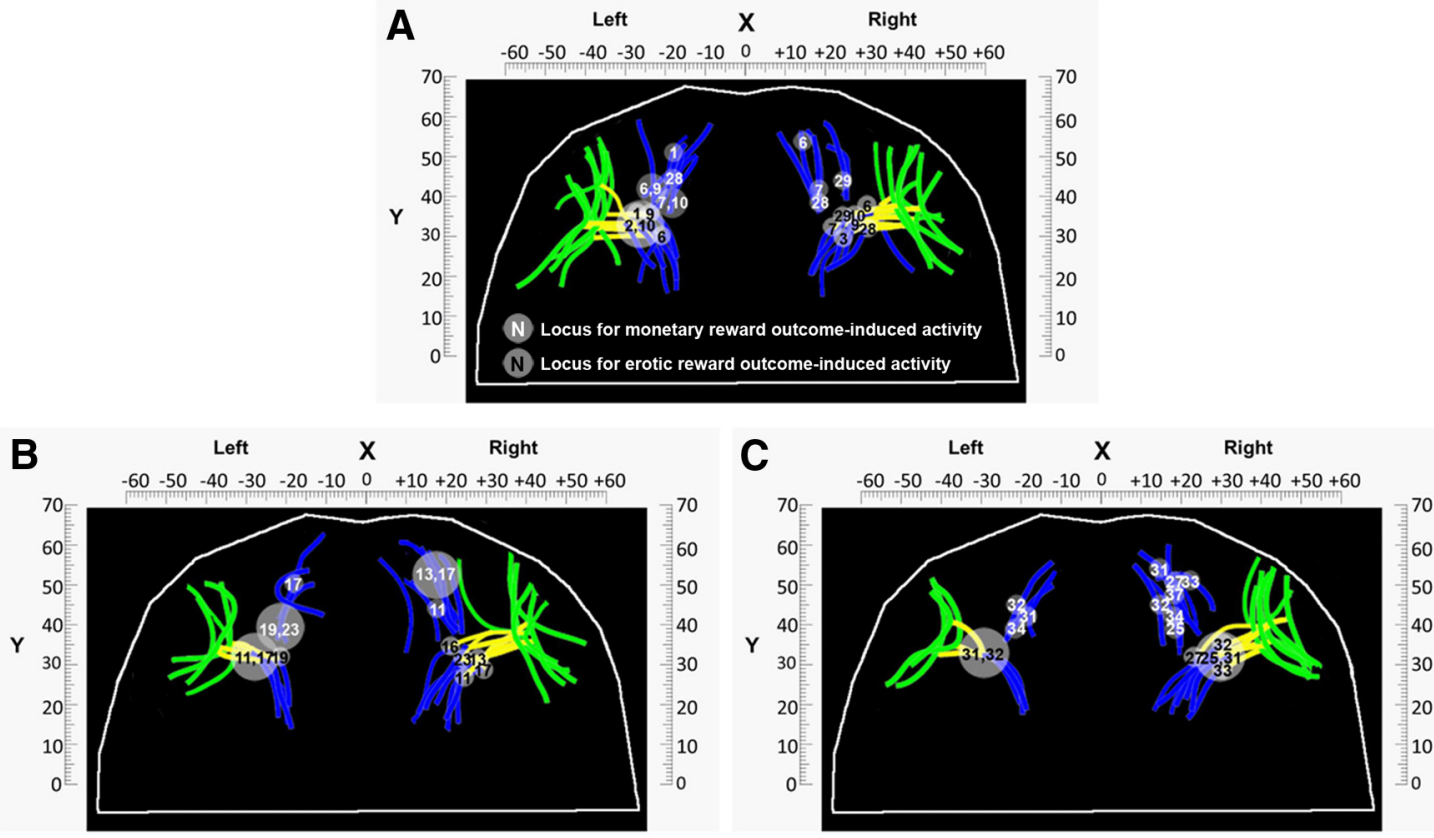

\section{Pattern Type I}

Figure 5. Anatomo-functional organization of the OFC's morphology of the pattern Type I in all subjects within each hemisphere. A-C, Locations of value signals at the time of monetary and erotic reward outcome for all subjects in both hemispheres grouped by the pattern Type I. To avoid overlapping of locations of experienced value signals across subjects, we present the results in three separate panels so that the relationship between experienced value signals and specific sulci locations can be illustrated clearly. Each dot indicates the location of the reward outcome-specific activity in each individual subject. Each number indicates the subject's number described in Tables 2 and 5 . White and black numerals indicate the experienced value signals for monetary and erotic rewards observed in the $\mathrm{OFC}$, respectively. Bigger circles with two numbers imply that these subjects to whom these numbers refer have the same MNI coordinates. As shown in the figure, all subjects displayed monetary reward-related activity in the MOSr. In contrast, all subjects display erotic reward-related activity at the intersection between the MOSC and TOS.

A

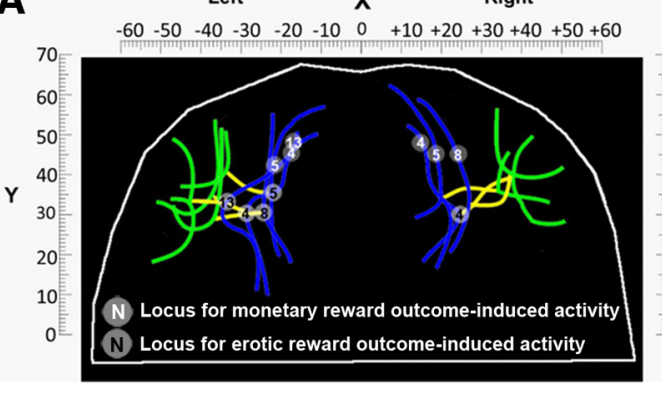

$\mathbf{x}$

$-60-50-40-30-20-10 \quad 0 \quad+10+20+30+40+50+60$
B

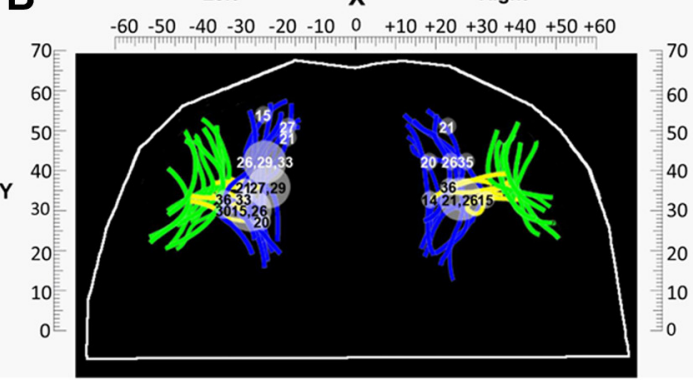

Pattern Type II

C

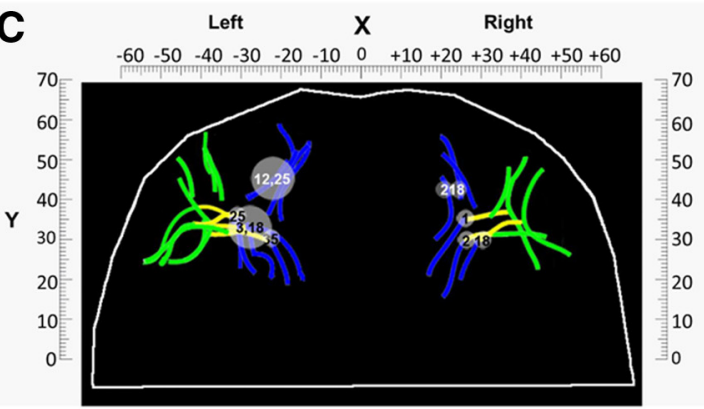

D

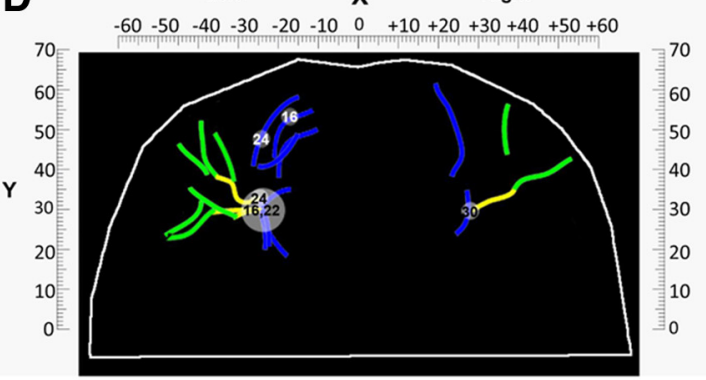

Pattern Type III

Figure 6. Anatomo-functional organization of the OFC's morphology of the pattern Type II and III in all subjects within each hemisphere. $A-D$, Locations of value signals at the time of monetary and erotic reward outcome for all subjects in both hemispheres grouped by the pattern Type II and Type III, respectively. To avoid overlapping of locations of experienced value signals across subjects, we present the results of each pattern type in two separate panels so that the relationship between experienced value signals and specific sulci locations can be illustrated clearly. Each dot indicates the location of the reward outcome-specific activity in each individual subject. Each number indicates the subject's number described in Tables 3, 4, 6, and 7. White and black numerals indicate the experienced value signals for monetary and erotic rewards observed in the $\mathrm{OFC}$, respectively. Bigger circles with two or three numbers imply that these subjects to whom these numbers refer have the same MNI coordinates. As shown in the figure, all subjects display monetary reward-related activity in the MOSr for these two orbitofrontal subcogyral types. In contrast, all subjects display erotic reward-related activity at the intersection between the MOSc and TOS for these two orbitofrontal subcogyral types. 
over, a recent meta-analysis study focusing on the neural correlates of stimulus values found dissociations in the ventromedial prefrontal cortex/OFC for different reward modalities (e.g., food vs money) (Clithero and Rangel, 2014). This study found that reward modality affected the precise location of ventromedial prefrontal cortex/OFC in which stimulus value was encoded, showing a postero-to-anterior gradient of value representations, corresponding to concrete-to-abstract rewards (Clithero and Rangel, 2014). This leads to a similar question about how stimulus value signals for different reward modalities map onto the local morphology of the OFC. Thus, our subject-by-subject data analysis scheme can provide guidance to report results in studies involved in other types of value signals in the OFC. As a consequence, our current analysis may contribute to a comprehensive understanding of the extent of such a hierarchy of value representation in this brain region.

Moreover, the establishment of clear anatomo-functional links is of critical importance, not only for our understanding of the functional organization of the OFC, but also for clinical purposes, such as targeting precisely the site of manipulations in cases of pharmacological resistant psychiatric conditions, and for providing clear guidance to surgeons for brain tumor removals (Amiez et al., 2008; Duffau, 2010, 2012; Peet et al., 2012).

Finally, one may still argue that erotic stimuli do not act as primary reinforcers and that, as a consequence, our data suggest that different types of secondary reinforcers are topographically organized. However, additional investigation involving additional types of primary reinforcers showed that food rewards also engaged the posterior part of the OFC (Kringelbach et al., 2003; Siep et al., 2009; Klein-Flügge et al., 2013; Sescousse et al., 2013b). In particular, a recent meta-analysis of 87 studies (1452 subjects) comparing brain responses with monetary, erotic, and food rewards confirmed that money-specific responses were observed in the most anterior portion of the OFC, whereas food and erotic (i.e., primary) rewards elicited activity in the posterior OFC (Sescousse et al., 2013b). However, the posterior OFC was also recruited by monetary rewards in this meta-analysis; therefore, specific recruitment of the posterior portion of the OFC requires further clarification in future research.

In conclusion, our study shows clear relationships between the local morphology of the OFC and experienced value signals in the human brain, depending on reward types. Such a conclusion can only be made on the basis of individual subject analyses that take into account individual morphological variations in the ROI, and not on the basis of group average analyses, because the variability in peak locations in the OFC globally decreases the statistical outcome in that region when averaging across subjects. As such, this conclusion has direct implications with regard to brain imaging methods, indicating that a single individual approach can be considered as an important complementary type of analysis to the conventional group average approach, by providing more detailed descriptions of the peak locations involved in a particular cognitive task. An exciting avenue for further work would be to generate cleaner taxonomies of reward type representation in the OFC, taking into account their complexity and how those might have distinct neural representations along the OFC gradient using the subject-by-subject analysis.

\section{Notes}

Supplemental material for this article is available at http://dreherteam. cnc.isc.cnrs.fr/en/httpdreherteamcncisccnrsfrpub/pub/. This material has not been peer reviewed.

\section{References}

Amiez C, Petrides M (2009) Anatomical organization of the eye fields in the human and non-human primate frontal cortex. Prog Neurobiol 89:220 230. CrossRef Medline

Amiez C, Petrides M (2014) Neuroimaging evidence of the anatomofunctional organization of the human cingulate motor areas. Cereb Cortex 24:563-578. CrossRef Medline

Amiez C, Kostopoulos P, Champod AS, Petrides M (2006) Local morphology predicts functional organization of the dorsal premotor region in the human brain. J Neurosci 26:2724-2731. CrossRef Medline

Amiez C, Kostopoulos P, Champod AS, Collins DL, Doyon J, Del Maestro R, Petrides M (2008) Preoperative functional magnetic resonance imaging assessment of higher-order cognitive function in patients undergoing surgery for brain tumors. J Neurosurg 108:258-268. CrossRef Medline

Amiez C, Neveu R, Warrot D, Petrides M, Knoblauch K, Procyk E (2013) The location of feedback-related activity in the midcingulate cortex is predicted by local morphology. J Neurosci 33:2217-2228. CrossRef Medline

Barbas H, Pandya DN (1989) Architecture and intrinsic connections of the prefrontal cortex in the rhesus monkey. J Comp Neurol 286:353-375. CrossRef Medline

Bartra O, McGuire JT, Kable JW (2013) The valuation system: a coordinatebased meta-analysis of BOLD fMRI experiments examining neural correlates of subjective value. Neuroimage 76:412-427. CrossRef Medline

Beck AT, Beck RW (1972) Screening depressed patients in family practice: a rapid technic. Postgrad Med 52:81-85. Medline

Carmichael ST, Price JL (1995) Limbic connections of the orbital and medial prefrontal cortex in macaque monkeys. J Comp Neurol 363:615-641. CrossRef Medline

Carmichael ST, Price JL (1996) Connectional networks within the orbital and medial prefrontal cortex of macaque monkeys. J Comp Neurol 371: 179-207. CrossRef Medline

Chiavaras MM, Petrides M (2000) Orbitofrontal sulci of the human and macaque monkey brain. J Comp Neurol 422:35-54. CrossRef Medline

Clithero JA, Rangel A (2014) Informatic parcellation of the network involved in the computation of subjective value. Soc Cogn Affect Neurosci 9:1289-1302. Medline

Deaner RO, Khera AV, Platt ML (2005) Monkeys pay per view: adaptive valuation of social images by rhesus macaques. Curr Biol 15:543-548. CrossRef Medline

Derrfuss J, Vogt VL, Fiebach CJ, von Cramon DY, Tittgemeyer M (2012) Functional organization of the left inferior precentral sulcus: dissociating the inferior frontal eye field and the inferior frontal junction. Neuroimage 59:3829-3837. CrossRef Medline

Duffau H (2010) New insights into pre-, intra- and post-operative brain mapping in low-grade glioma surgery: towards a longitudinal study of cerebral plasticity. Curr Med Imaging Rev 6:246-253. CrossRef

Duffau H (2012) Brain mapping: from neural basis of cognition to surgical applications. New York: Springer.

Grabenhorst F, Rolls ET (2011) Value, pleasure and choice in the ventral prefrontal cortex. Trends Cogn Sci 15:56-67. CrossRef Medline

Grosbras MH, Lobel E, Van de Moortele PF, LeBihan D, Berthoz A (1999) An anatomical landmark for the supplementary eye fields in human revealed with functional magnetic resonance imaging. Cereb Cortex 9:705711. CrossRef Medline

Haber SN, Knutson B (2010) The reward circuit: linking primate anatomy and human imaging. Neuropsychopharmacology 35:4-26. CrossRef Medline

Hoon E, Chambless D (1998) Sexual arousability inventory and sexual arousability inventory-expanded. In: Handbook of sexuality-related measures (Davis C, Yarber W, Bauserman R, Schreer R, Davis S, eds.), pp 71-74. Thousand Oaks, CA: Sage.

Kahnt T, Chang LJ, Park SQ, Heinzle J, Haynes JD (2012) Connectivitybased parcellation of the human orbitofrontal cortex. J Neurosci 32: 6240-6250. CrossRef Medline

Kim H, Shimojo S, O’Doherty JP (2011) Overlapping responses for the expectation of juice and money rewards in human ventromedial prefrontal cortex. Cereb Cortex 21:769-776. CrossRef Medline

Klein-Flügge MC, Barron HC, Brodersen KH, Dolan RJ, Behrens TE (2013) Segregated encoding of reward-identity and stimulus-reward associations in human orbitofrontal cortex. J Neurosci 33:3202-3211. CrossRef Medline 
Kringelbach ML (2005) The human orbitofrontal cortex: linking reward to hedonic experience. Nat Rev Neurosci 6:691-702. CrossRef Medline

Kringelbach ML, Rolls ET (2004) The functional neuroanatomy of the human orbitofrontal cortex: evidence from neuroimaging and neuropsychology. Prog Neurobiol 72:341-372. CrossRef Medline

Kringelbach ML, O'Doherty J, Rolls ET, Andrews C (2003) Activation of the human orbitofrontal cortex to a liquid food stimulus is correlated with its subjective pleasantness. Cereb Cortex 13:1064-1071. CrossRef Medline

Levy DJ, Glimcher PW (2012) The root of all value: a neural common currency for choice. Curr Opin Neurobiol 22:1027-1038. CrossRef Medline

Mackey S, Petrides M (2009) Architectonic mapping of the medial region of the human orbitofrontal cortex by density profiles. Neuroscience 159: 1089-1107. CrossRef Medline

Mainen ZF, Kepecs A (2009) Neural representation of behavioral outcomes in the orbitofrontal cortex. Curr Opin Neurobiol 19:84-91. CrossRef Medline

Maldjian JA, Laurienti PJ, Kraft RA, Burdette JH (2003) An automated method for neuroanatomic and cytoarchitectonic atlas-based interrogation of fMRI data sets. Neuroimage 19:1233-1239. CrossRef Medline

McNamee D, Rangel A, O’Doherty JP (2013) Category-dependent and category-independent goal-value codes in human ventromedial prefrontal cortex. Nat Neurosci 16:479-485. CrossRef Medline

Mouras H (2007) Central role of somatosensory processes in sexual arousal as identified by neuroimaging techniques. Behav Brain Sci 30:217. CrossRef

Murray EA, O'Doherty JP, Schoenbaum G (2007) What we know and do not know about the functions of the orbitofrontal cortex after 20 years of cross-species studies. J Neurosci 27:8166-8169. CrossRef Medline

Ongür D, Price JL (2000) The organization of networks within the orbital and medial prefrontal cortex of rats, monkeys and humans. Cereb Cortex 10:206-219. CrossRef Medline

Ongür D, Ferry AT, Price JL (2003) Architectonic subdivision of the human orbital and medial prefrontal cortex. J Comp Neurol 460:425-449. CrossRef Medline

Peet AC, Arvanitis TN, Leach MO, Waldman AD (2012) Functional imaging in adult and paediatric brain tumours. Nat Rev Clin Oncol 9:700-711. CrossRef Medline

Peters J, Büchel C (2010) Neural representations of subjective reward value. Behav Brain Res 213:135-141. CrossRef Medline

Petrides M, Mackey S (2006) Gyral morphology and architecture. Orbitofrontal cortex (Zald D, Rauch S, eds.), pp 19-37. Oxford: Oxford UP.

Prévost C, Pessiglione M, Météreau E, Cléry-Melin ML, Dreher JC (2010) Separate valuation subsystems for delay and effort decision costs. J Neurosci 30:14080-14090. CrossRef Medline
Price JL (2006) Connections of orbital cortex. In: Orbitofrontal cortex (Zald D, Rauch S, eds.), pp 39-55. Oxford: Oxford UP.

Price JL (2007) Definition of the orbital cortex in relation to specific connections with limbic and visceral structures and other cortical regions. Ann N Y Acad Sci 1121:54-71. CrossRef Medline

Rolls ET, McCabe C, Redoute J (2008) Expected value, reward outcome, and temporal difference error representations in a probabilistic decision task. Cereb Cortex 18:652-663. CrossRef Medline

Ruff CC, Fehr E (2014) The neurobiology of rewards and values in social decision making. Nat Rev Neurosci 15:549-562. CrossRef Medline

Segal E, Petrides M (2013) Functional activation during reading in relation to the sulci of the angular gyrus region. Eur J Neurosci 38:2793-2801. CrossRef Medline

Sescousse G, Redouté J, Dreher JC (2010) The architecture of reward value coding in the human orbitofrontal cortex. J Neurosci 30:13095-13104. CrossRef Medline

Sescousse G, Barbalat G, Domenech P, Dreher JC (2013a) Imbalance in the sensitivity to different types of rewards in pathological gambling. Brain 136:2527-2538. CrossRef Medline

Sescousse G, Caldú X, Segura B, Dreher JC (2013b) Processing of primary and secondary rewards: a quantitative meta-analysis and review of human functional neuroimaging studies. Neurosci Biobehav Rev 37:681-696. CrossRef Medline

Sescousse G, Li Y, Dreher JC (2014) A common currency for the computation of motivational values in the human striatum. Soc Cogn Affect Neurosci. Advance online publication. Retrieved May 16, 2014. doi: 10.1093/ scan/nsu074. CrossRef Medline

Siep N, Roefs A, Roebroeck A, Havermans R, Bonte ML, Jansen A (2009) Hunger is the best spice: an fMRI study of the effects of attention, hunger and calorie content on food reward processing in the amygdala and orbitofrontal cortex. Behav Brain Res 198:149-158. CrossRef Medline

Sugrue LP, Corrado GS, Newsome WT (2005) Choosing the greater of two goods: neural currencies for valuation and decision making. Nat Rev Neurosci 6:363-375. CrossRef Medline

Tzourio-Mazoyer N, Landeau B, Papathanassiou D, Crivello F, Etard O, Delcroix N, Mazoyer B, Joliot M (2002) Automated anatomical labeling of activations in SPM using a macroscopic anatomical parcellation of the MNI MRI single-subject brain. Neuroimage 15:273-289. CrossRef Medline

Wallis JD (2007) Orbitofrontal cortex and its contribution to decisionmaking. Annu Rev Neurosci 30:31-56. CrossRef Medline

Zigmond AS, Snaith RP (1983) The hospital anxiety and depression scale. Acta Psychiatr Scand 67:361-370. CrossRef Medline 